\title{
Digitalisation in the Food Industry - Case Studies on the Effects of IT and Technological Development on Companies
}

\author{
Judit Nagy, Zsófia Jámbor, Anna Freund \\ Corvinus University of Budapest, Hungary
}

\begin{abstract}
In recent decades as a result of the development of information and communication technologies (ICT) and the Internet, we have witnessed major changes in companies. The ICT support of the processes is becoming more and more extensive and comprehensive, which enables the realization of digitalisation. The interconnection of processes, machines, people in a single network makes another level of optimisation available. The changes turned up by digitalisation are not only technological, but they also have an impact on the company's organisation and strategy. Our study aims to create an analytical framework and map the opportunities that digitalisation promises in the food industry and the organisational changes that ICT and technological development bring, with special emphasis on the impact on strategy, employees, and corporate culture. Our results show that companies are not consciously engaged in digitalisation yet, but they exploit their opportunities and make improvements in this sense. Adaptation of digital solutions is often forced by the labour shortage, the pressure to achieve higher efficiency and thus to remain competitive and to service the growth strategy.
\end{abstract}

\section{Keywords}

Digitalisation, ICT development, food industry, strategy, interviews.

Nagy, J., Jámbor, Z. and Freund, A. (2020) "Digitalisation in the Food Industry - Case Studies on the Effects of IT and Technological Development on Companies", AGRIS on-line Papers in Economics and Informatics, Vol. 12, No. 4, pp. 77-92. ISSN 1804-1930. DOI 10.7160/aol.2020.120406.

\section{Introduction}

The development of information and communication technologies (ICT), database systems, and increasing digitalisation is a hot topic not only in the corporate but also in the academic sphere. Robots and automation have long existed, but the Internet (or any internal company network like this) is revolutionizing process management by connecting them into a network. Thanks to the increasing digitalisation, the company's devices, and machines, and in some cases the products themselves can connect and cooperate, realizing Industry 4.0 (I4.0). Devices such as sensors, RFID chips, 3D scanners, cameras, and robots generate data that literature calls big data. It is a huge challenge to store, process, and interpret, and is essential for the implementation of I4.0 (Hermann et al., 2016; Ilie-Zudor et al., 2011). Digitalisation is not only an ICT development, its extensive use in the company processes also affects the organisation (Horváth and Szabó, 2019), employees (Frey and Osborne, 2017), and business partnerships (Pagani and Pardo, 2017).
Most of the published studies deal with digitalisation from a technological point of view (Dworschak and Zasier, 2014; Hermann et al., 2016) or a theoretical point of view (Fettig et al., 2018; Dalenogare et al., 2018) however, the number of studies presenting specific company cases is limited. The impact of digitalisation and I4.0 is most significant in the electronics and machine industry, most of the research reports illustrate their solutions (Demeter et al., 2020; Nagy, 2018; Horváth and Szabó, 2019; Gauger et al., 2017). In our study, we focus on another manufacturing sector, the food industry, which is not a typical subject of digitalisation studies. Robotics and automation have long been present in many subsectors of the food industry. Real-time data streaming, big data, and information sharing, first and foremost within the company and then at the supply chain level, are of paramount importance for food safety and tracking purposes, and industrial digitalisation solutions offer many opportunities to improve these areas. 


\section{World trends in the food industry}

Due to global trends, it is very important to focus on the agriculture and food industry: on the one hand, to supply a growing world population, more efficient production and processing are needed, and on the other hand, guaranteeing food safety is already a global requirement. The world population has tripled since the $1950 \mathrm{~s}$, reaching over 7.8 billion in February 2020. This figure, although slowing, continues to grow and is estimated to exceed well over nine billion by 2050 (Chaime, 2020). The World Economic Forum estimates that food demand will increase by nearly $70 \%$ so far (World Economic Forum, 2018). Another important aspect is that with the development of the countries, due to the increase of the living standard of the population, the amount of food to be consumed changes significantly, the energy demand of the population is much higher and the daily intake of animal protein is increasing (Sen et al., 2017). Meeting growing and changing demand and reducing and relieving environmental impacts mean major challenges for farms as well as actors in both agriculture and the food industry (Demartini et al., 2018).

One of the industries most exposed to the variability of consumer demand is the food industry. Even if the quantity needed does not change dramatically, the type of products demanded - e.g. increasing trend of healthy food-causes significant changes (Carpenter and Wyman, 2017). The production of healthy foods requires new, high-quality ingredients and production methods, which can reduce sugar and/or fat content, use alternative substitutes, and retain higher levels of vitamins and minerals. The food industry should take into account for example Europe's aging societies and changing nutrition needs, and childhood obesity, as a growing problem in the developed world when developing (new) products (Santeramo et al., 2018).

In addition to consumer trends, the food industry also has to cope with pressure from retailers, which means lower prices, higher quality, a constantly renewed range of products, and, of course, unquestionable food security (Kittipanya-ngam and Tan, 2020). To address these challenges from both sides, the development of ICT, digitalisation, and I4.0 tools can provide solutions.

Regarding the structure of the paper, after we give a brief description of the world food industry trends and the possibilities of ICT-based digitalisation and I4.0, in the methodological section we present the theoretical framework we used for the analysis and the method and process of the case studies. The fourth section summarises the experiences of the company interviews, after which we conclude. Finally, research limitations and future research directions will be presented.

\section{Industry 4.0 and digitalisation in the food industry}

IT-based automation and robotization have long been present in many subsectors of agriculture and the food industry (e.g. pasta, dairy), while in others are only partially applicable, because of the high demand for human workforce since processes are poorly standardized or too sophisticated (meat industry, bakery products). As Kittipanya-ngam and Tan (2020) states, there is not a single ICT solution for digitalising the food industry and agriculture processes. According to Simutech (2016), machine downtime in food processing can cost up to $\$ 30,000$ per hour, so the use of in-process predictive maintenance sensors to prevent machine failure can quickly pay off. Processes made transparent with sensors can help increasing energy efficiency, reducing rejected deliveries and waste. Agility, rapid machine change-over, and the ability to produce smaller series are important considerations when selecting new technology (Carpenter and Wyman, 2017).

Meeting the changing customer demand also transforms and accelerates the product development process. With 3D printing, the prototype of either the product itself or the advanced packaging is shortened, so consumer testing can be accomplished in a much shorter time.

According to experts (Bibi et al., 2017; Carpenter and Wyman, 2017; Bottani and Rizzi, 2008), food safety and traceability are definitely the areas where information and database systems as the representatives of I4.0 can greatly support the management of agriculture and food industry. For example, identification systems based on the EPC Global system can trace raw materials incorporated into food and/or packaging from the place of origin to the place of use. Thus, in case of any problem or product recall, the affected product series can be clearly identified and quickly withdrawn from the market (Bibi et al., 2017; Carpenter and Wyman, 2017).

Researchers see blockchain technology as an appropriate tool for food monitoring (Tian, 2016; Tse et al., 2017). As discussed in the previous paragraph, ICT based solutions, such as RFID, 
barcode, and wireless sensors are well-suited to the food supply chain for transparency and traceability reasons, and especially for data collection and transmission. However, we need a medium that makes this information visible (Carlozo, 2017). Blockchain raises the level of trust by making the flow of data, goods, or money transparent and traceable.

Thus, both the agriculture and the food industry can take advantage of the ICT based I4.0 applications and the solutions offered by digitalisation, in many ways. However, some technologies and information and database connected methodologies are either expensive, immature, or have little practical experience, so there is no benchmark for learning.

Our research question is how do food industry companies perceive the realization of digitalisation and ICT based improvements in their operations and organisation? The novelty of our paper is twofold. On one hand, we create a research framework, which helps systematically analyse a company's digital situation. Besides the applied ICT solutions, we invoke additional research aspects and propose to analyse digitalisation's effects on strategy, organisation, employees, and company culture. On the other hand, until now only a few academic papers have analysed the presence and effects of I4.0 and digitalisation in the food industry. Our results widen the knowledge on digitalisation in the food industry, point out its effects not only on technology but on the entire organisation, and could be benchmarks for practitioners, too.

\section{Materials and methods}

To systematically examine the impact of I4.0 and digitalisation on the food industry companies, we looked for relevant analytical aspects in the literature. The purpose of this analysis is to get to know how I4.0 and digitalisation transform the entire company as well as to call the attention of business professionals that I4.0 not only affects the technology in a company, but also the organisation itself.

The paper presents case studies that are based on four interviews and were conducted in the three largest subsectors of the Hungarian food industry. According to Yin (2011), a case study is an appropriate methodology when researchers want to understand how digitalisation affects companies and aims to gain a better understanding of what and why firms decide and do to move towards I4.0. The case studies are not intended to produce generalizable or representative results (Denzin and Lincoln, 2011), however, they might help to identify good practices in the sector and further directions for improvement.

\section{Analytical framework}

To get a broad picture of how I4.0 affects the organisation we tried to identify relevant analytical dimensions. We found that I4.0 maturity models involve a great variety of aspects, which seemed to be useful for our analysis, too. Many authors and consulting companies have developed maturity models that evaluate companies in several aspects before determining their degree of maturity and many of these aspects are common. We do not aim to examine the maturity of the analysed companies, because the sample size is not large enough, but some maturity dimensions can serve as a basis for our analysis because they examine the individual organisations (Table 1). In the following, three highly cited maturity models are presented and compared to determine our analytical framework.

The most cited maturity model comes from Schumacher et al. (2016), who examine companies' digital status from nine perspectives. The analytical dimensions include strategy, leadership, customers, products, operations, technology, culture, people, and governance. The study does not detail the nine assessment factors but reveals that they are built of another 62 dimensions. As we can see, Schumacher et al. analyse the effects of I4.0 on the organisation from various points of view, which suggests us not to narrow our investigation only to technology. From amongst the aspects, organisational adaptation is clearly lacking.

Geissbauer et al. (2016) have formulated a maturity model that involves cross-company digital connectivity with customers, suppliers, and other stakeholders, who are all integrated horizontally and vertically into a digital ecosystem. The scope of the analysis is very broad, besides the digital business model (change of strategy), agile IT infrastructure, and data analysis, many new aspects are emerging, including organisation, taxation, and data analysis. In their approach, I4.0 also has a comprehensive effect on organisations, besides technological improvement.

Schuh et al. (2017) developed a complex index to measure the maturity of companies in I4.0. They examine the structural characteristics of firms such as resources, organisational structure, information 


\begin{tabular}{|l|l|c|}
\hline Authors & \multicolumn{1}{|c|}{ Aspects of maturity analysis } & $\begin{array}{c}\text { No. of citations } \\
\text { (Google Scholar) }\end{array}$ \\
\hline Schumacher et al., 2018 & $\begin{array}{l}\text { Strategy, Leadership, Customers, Products, Operations, Technology, Culture, } \\
\text { People, Governance }\end{array}$ & 415 \\
\hline Geissbauer et al., 2016 & $\begin{array}{l}\text { Digital business models and customer access, Digitization of product and } \\
\text { service offerings, Digitization and integration of vertical and horizontal value } \\
\text { chains, Data \& Analytics as core capability, Agile IT architecture, Compliance, } \\
\text { security, legal and tax, Organization, employees and digital culture. }\end{array}$ & 198 \\
\hline Schuh et al., 2017 & $\begin{array}{l}\text { Structure: Resources, Organizational structure, Information system, Culture } \\
\text { Processes: Functional areas (Development, Production, Logistics, Services, } \\
\text { Marketing \& Sales) }\end{array}$ & 76 \\
\hline
\end{tabular}

Source: own edition

Table 1: Maturity models examined.

systems, and culture. Corporate processes are also reviewed along with functional areas, and performance is evaluated also along with the functional areas. The specialty of this approach is that the maturity of the functional areas underpins the maturity of the entire company. On the other hand, this approach is not fortunate, because the primary area of I4.0 development is usually manufacturing (Hofmann and Rüsch, 2017; Brettel et al., 2014), and other functional areas are usually followers if developed at all. Overall, this model can give us a complete picture of the development of a company in I4.0, since a company should not be judged solely on the level of development of its manufacturing process.

The Schuh-model combines analytical aspects that are already present in earlier maturity models in many ways. The resource category includes all movable resources - machines, products, tools, materials - including people and their abilities. The information systems category includes all formal communication solutions, including ICT (information and communication technology). The organisational structure examines the existence of an agile organisation and inter-company relationships that allow developing technology and continuous adaptation. Culture captures the soft side of all this, such as knowledge management, decision-making, corporate values, and the support of innovation. Thus, the company and the functional units are analysed according to these aspects, in the form of a questionnaire.

We do not include it in the analysis, but there are other (less-cited) maturity models that try to extend the above ones or similar to them. In their model, Lichtblau et al. (2015) propose six criteria for determining the maturity of companies. These six aspects are broken down into a further 18 in detail, very similar to Geissbauer's. According to Gracel and Łebkowski (2018), the Manufacturing
Technology Maturity Model (MTMM) wants to categorize companies along with the digital support of manufacturing, but in fact, they did an extensive analysis based on eight dimensions, already mentioned in the previous models and primarily focused on manufacturing. The maturity model presented by Gill and Van Boskirk (2016) is short and concise, analysing companies from four perspectives: culture, technology, organisation, and insights. The latter involves data analysis, the ability of the company to analyse and use data from customers or processes to support the strategy.

From the maturity models presented and the underlying analytical considerations, we will use the dimensions that evenly appear in the models. Technological improvements to gain a better data collection and analysis are the basis of the developments within a company, and since the maturity models emphasize the issue, we included it into our analysis, too. The extensive technological advances - not only in data-issues but in manufacturing and other areas, too - are another characteristic projection of I4.0, which we obviously need to analyse. After these two fundamental changes that typically occur in every company, we wanted to examine the effects of I4.0 on the organisation from multiple aspects. First, we choose employees, since they are the ones who use the new technology and provide or analyse data, make decisions. Because of the probable changes in the decision-making process, we also keep it important to get to know-how strategy and organisational structure as well as the company culture changed. These aspects can also be derived from the cited maturity models.

The purpose of this paper is not to determine the degree of maturity, but to provide a structured presentation of the technological and organisational development that is taking 
place in the studied companies as a result of digitalisation. We will apply analytical dimensions of strategy and organisation, data analysis, technology, employees, and corporate culture to highlight how the Hungarian food industry companies move towards I4.0. The relationship between these and the most important competitive factors for the food industry is illustrated in Figure 1.

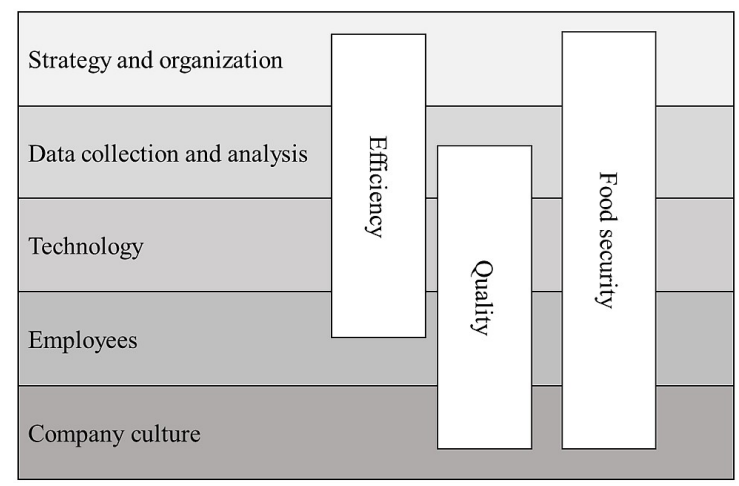

Source: own construction

Figure 1: Relationship between research aspects.

The figure summarises the five analytical dimensions along which the interviewed companies will be analysed. The three most important competitive factors - efficiency, quality, and food security - were derived from the literature review and are the largest challenges of today's food industry. We are intended to analyse how these competitive factors are affected by the changes indicated by digitalisation. The most important factors in increasing efficiency - which, according to Kürthy et al. (2016), is a serious lag in the Hungarian food industry - are the strategy which incorporates the understanding of the firm's actual situation and the adaptation, the technology which is changed as a result of educating employees, and uses the resulting data for further optimisation. Technology also has a great impact on quality, and by analysing the data, it can be further developed, faster prototype production and testing can be achieved. Commitment to quality must also be part of the corporate culture, which is reflected in the work of the employees. Digital developments in all areas serve a high level of food safety and traceability. Overall, the analytical aspects of the interviews will therefore help better understanding the three competitive factors.

\section{Case studies}

Following the above-identified analytical aspects, we edited interview questions to get insight into the companies' I4.0 practice, motives, and achievements. Data were collected from four food companies in Hungary, whose names will not be disclosed upon request. The most important data on the investigated companies are presented in Table 2.

The interview questions started with a strategy. We asked the companies about their market, the changes they experience, and the possible answers they are giving to these changes. he data collection, analysis, and other technological improvements were asked as to what kind of improvement projects have been carried out or planned at the companies. We also asked them about how and what extent the employees are involved in the development process, and how he changes affected them. We were curious about the organisational changes caused by I4.0, for example, new positions or the probable downsizing. The company culture was captured by questions like how employees adapted to changes, what steps the companies do to make the staff accept the new technologies.

We made 1.5-2 hours long structured interviews with company executives, and we talked about the company's I4.0 approach, the digitalisation solutions used, the projects, and the directions of development. As all interviewees were top executives of a given company, they were aware of both production and strategic issues and were considered relevant sources of information. The reliability of our research is enhanced

\begin{tabular}{|c|c|c|c|c|}
\hline $\begin{array}{l}\text { Company } \\
\text { Characteristics }\end{array}$ & "A" & "B" & "C" & "D" \\
\hline Sub-sector & $\begin{array}{c}\text { pasta } \\
\text { manufacturing }\end{array}$ & dairy production & dairy processing & meat processing \\
\hline Location & Western-Hungary & Western-Hungary & Western-Hungary & Eastern-Hungary \\
\hline Interviewee & plant manager & farm manager & plant manager & CEO \\
\hline
\end{tabular}

Source: own construction 
by the fact that although the number of interviews is low, they were conducted with the three largest subsectors of the Hungarian food industry, the meat industry, the dairy industry, and the bakery and pasta industry. Three of the four firms are market leaders in their sub-sector, but because of confidentiality reasons, we cannot reveal them.

Based on these, our experience with the digitisation of the food industry in Hungary is diverse. The wide range of technologies and solutions used in the automotive industry (Nagy, 2018; Demeter et al., 2020) is far from that of the food sector. At the same time, it is very important that many processes have long been robotized and/or automated in the food industry, otherwise, the efficiency and food safety that customers and the authority expect of companies would not be achieved. However, the further development of these, I4.0, digitalisation, and the exploitation of big data are in the focus of corporate thinking.

\section{Results and discussion}

In this section, we will examine companies' I4.0 practices according to the analytical framework created in Chapter 2.1.

\section{Strategy and organisation}

In the strategy and organisation analytical dimension, we examined phenomena such as the existence of the I4.0 strategy or the effect of I4.0 on strategy. We examined whether the organisational structure has changed as a result of digitalisation. It was also interesting where the initiation of improvements began.

For two of the four companies examined, the move towards I4.0 was induced by the growth strategy. With the capacities available before the developments, they were no longer able to further increase production, so a decision had to be made as to whether they were satisfied with the current size of their business or wanted to grow. The latter was chosen by both of them and the new technologies purchased include digital solutions.

With the investments made, the pasta factory has multiplied its output capacity, since it aimed to increase its domestic market share and conquering the export markets. We cannot talk about specific I4.0 strategy, but when building the new factory and selecting the technology, they clearly wanted to take advantage of the opportunities offered by digitalisation: "The factory is $21^{\text {st }}$ century standard, so far we have focused on it. Now, the coming years will be more about how we can support the back-office activities, which is also important." In the case of the company, organisational changes have not yet taken place, but they already see the need, because the number of employees in the IT and maintenance departments has started to grow significantly. High-volume developments - such as choosing the technology for the new factory - was a top management decision, but operators were also involved in the design, fine-tuning and minor improvements.

In the case of the dairy production company, in addition to growth, survival and regulatory compliance also contributed to the technology innovation decision. The plant was obsolete by the end of the $2000 \mathrm{~s}$, and it was not possible to grow or increase efficiency with the existing number of workforce and technology: "Company decided to develop this plant". Regulatory standards also tightened, so they definitely had to improve. To this end, "a large-scale project was launched and one of the best and most efficient sites nationwide was established" - as our interviewee told us. As a result of the development, it was also possible to collect data that could be used to further increase animal welfare. In this case, we cannot talk about a developed I4.0 strategy, nor have any organisational changes been reported.

The dairy processing company is a member of an international group with a well-defined I4.0 strategy, and the Hungarian subsidiary also has responsibilities to fulfil it. According to the interviews, we distinguish between grouplevel developments that focus primarily on big data and analysis, improving forecasting and planning accuracy; and smaller, local-level developments that utilize I4.0 and digitalisation solutions to address a specific enterprise problem. "We realize our ideas and a lot of things that have already been implemented in other factories in the group, we take over here." The most common force that triggers local development is the lack of manpower, which they try to solve with partial automation and robotization. The company, through the projects implemented, is explicitly seeking to increase food safety and to meet or exceed standards. The C-level director of digital development is present at the international level only, in the Hungarian factory there is no dedicated leader. Local development can come from any level of the organisation, and operators are motivated to submit their proposals.

For a meat processing company, there is no explicit I4.0 strategy as well: "It will affect 
the industry within 5 to 10 years (I4.0). Now it's only in the minds of those executives who are open." In their case, the developments began as a result of a risk analysis that revealed the jobs where the risk of a labour migration would seriously jeopardize the operation of the plant. Subsequently, steps were taken to automate and robotize these operations. The other direction of development when building a new plant was sensory data collection, monitoring of the meat processing process, and thus increasing process efficiency. The sources of development proposals are mainly senior management, but employees at the bottom of the organisational hierarchy also have the opportunity to submit ideas. Organisational changes have not yet occurred due to digitalisation.

We have found that the companies are changing, but in all cases, the digital transformation is underway, the starting point is mainly top management decided to move the company towards growth and efficiency. The specialty of the food industry is that better compliance with regulations also motivates the developments, as it was suggested by Kittipanya-ngam and Tan (2020) and Carpenter and Wyman (2017). We also found that, although improvements had begun, this did not change the strategy, there was no formal I4.0 strategy and the transformation of the organisation to the new business model had not yet begun. Amongst the reasons for the development of changing customer needs and retailers, the pressure was not identified in the case companies, contrary to literature.

\section{Data collection and analysis}

The purpose of this section is to explore what data the companies collect, and how it is collected, processed, and used in decision making.

The pasta company has intended to take advantage of the technology when designing the new production facility and gathers as much data as possible about the production process. The raw material entering the automatic production line passes through sensors of weight and humidity. The consistency of the dough being made is also controlled and so is the temperature of the dryer. The finished pasta passes through several control points both before and after packaging, where any piece of metal found in the production process is screened with a metal detector and the weight and bar code of the package are also checked. The machines are equipped with preventive maintenance sensors (operating hours meter), any deviation from the norm can be detected immediately and the necessary intervention can be decided. The manufacturer also provides remote diagnostic services and uploads maintenance tasks to be performed when a particular operating hour is reached. The goal is to reduce downtime or, if there is a downtime, to find the causes and avoid them next time. Based on these, the maintenance task can be scheduled, employees receive the task on a tablet, which informs them what task to perform, what materials to use, what error to correct (or not if it failed). There is also a monthly report on the machine's performance and operating characteristics. Analysing data is a big task for a company. By their own admission, they did not expect the analysis of the extracted data to be so important when building the new plant, so the development of the supportive IT background is lagging. Their goal is to have the most important data instantly online and make real-time decisions: "So if the production manager wants to look at the production, then he doesn't have to look at the machine and see what happens, he just takes out his notebook and can watch the process."

The technology of the dairy production company enables the collection of a large amount of data. At starting the dairy production process, animals are individually identified using an RFID chip hanging in their ears. This chip stores the animal's identity, breed, ancestry, physical characteristics (e.g. lactation phase), and all interventions in which the animal was involved (vaccinations, calving, etc.). Milk yields from individual cows are also known, so when the animal arrives at the milking machine, it calculates an expected milk yield: "If the cows at the start of lactation, then obviously the expected amount of milk is up, if she is the end of lactation the milk production will keep going down then the system obviously will change the expectations day by day. We get a lot of data from this device." If the expected milk yield is not met, it will be checked first if the milking machine has been set up correctly, and if the yield is less than expected for an extended time period, the animal will be examined by a veterinarian. The milking machine also checks the quality and composition of the milk that is being milked. It can calculate from the milk flow rate whether the milking worker has properly triggered the milking reflex (that is, the animal has given as much milk as possible), which is also reflected in the performance pay. The milking machine allows access to a variety of reports. The milking process can be queried in different compositions and focus. Latter are determined and evaluated by the animal 
breeding engineer. The availability of preventive maintenance and remote diagnostics was an important consideration when choosing the technology. The manufacturer constantly monitors the condition of the machines and makes recommendations for necessary maintenance. The feed consumed by the animals is also recorded in the computerized system. Cows are grouped according to their age, milk yield, lactation status, and receive a feed of appropriate quality and quantity. The composition of the fodder needed for a group of animals is determined by the feeding manager who uploads it into a flash drive and from that onto the feed mixing machine, which indicates which type of feed to load (by weight) and then mixes them.

Digital development, encouraged by the parent company of the dairy processing firm, is data collection and analysis. They are already trying to extract and analyse data from the PLC (Programmable Logic Controller). This can be a great help in preventive maintenance or even avoiding quality problems e.g., the scales built into the production process can monitor which component is being dosed and, if out of range, suggest which component should be added more, which is less. Tracing allergenic substances is also a requirement for food safety: "In our industry, traceability of batches is very important, especially if the product contains allergenic substances." The aim is to see production data that allows immediate intervention.

Developments that ensure food safety and compliance with official regulations are of paramount importance to the company, as the internal rules of the international group are stricter than Hungarian or even EU rules. For example, when a component is added to a product, it is recorded in which raw material is blended from which supplier's production batch, thus ensuring traceability. This tracking is even more thorough with allergenic materials when it is also recorded who cleaned the machine after production.

The meat processing company deliberately chose digital technology to monitor processes and closely control the production line at its new plant, thereby helping to increase the accuracy of data control and process efficiency, and to support performance pay: "we built in everything that can provide data for ERP, controlling and process control". Another area of data collection is the monitoring of machine conditions for preventive maintenance. Machine shutdown is a major cost factor in this sector as well, and an important reason for the development of data collection in this area.

Collecting and analysing data was a very important factor in every company when choosing technology. Companies also report that they have a wealth of data and are struggling to process it and turn it into relevant information that they can use in real-time decision-making. At the same time, it seems that the production and storage of data is just one problem, the other is the development and purchase of software and systems that can analyse and display them. Food safety - as a reason behind developments - came up several times during interviews, as the literature claims (Kittipanyangam and Tan, 2020). However, the literature does not address the cost and challenge of building and operating such IT systems at companies that can store and share data of quality and composition compliant with food safety regulations. Although blockchain would be a suitable technology for solving this problem, we have not identified any traces of the application in the Hungarian company practice, yet. An appropriate system for data collection and analysis is challenging in all respects and companies are investing significant sums in this regard.

\section{Technological solutions}

In this section, we present all the technological solutions - be it automation, robotics, or IT development - that have resulted in great progress in the company in terms of both efficiency and data processing. We also cover the issues of data security and cyber security that concern companies.

The pasta company is implementing a high degree of automation and robotization in its new factory. The production of the dough goes through an automatic process from the breaking of the eggs to the unloading of the finished and packed pasta in the form of a unit load. In the dough-making machine, sensors monitor the dough's texture, moisture, humidity, and temperature. Heat recovery is built in the drying process, which allows significant energy savings. The packaging is carried out by an automatic packaging line after production. After several weighing and metal detector screening, the pasta packages are placed in a cardboard box and then conveyed by the conveyor to the warehouse preparation area. Here, unit-loading robots receive the boxes and form stacks of products of the same type identified by barcode scanning. The stacks are captured by the wrapping machine and then, 
through it, an automatic signal is sent to the AGV (automatic guided vehicle) forklifts, which, after identification, transfer the unit load to the high bay racks warehouse designated for end products and hand it over to the high bay racking machine. When the unloading request is received, the former process is reversed, the racking machine finds the desired unit load, hands it over to the automatic forklift, and it forwards it to the delivery area.

Sensors built into the above process (balance, barcode scanner, metal detector, etc.) continuously produce data that is stored on company servers. The plant manager highlighted cyber security, which they try to secure through operating their own server and differentiating permissions.

When purchasing the technology, the possibility of connecting the machines and equipment to each other and the production centre was especially important. Remote diagnostics allow the company to detect the fault much faster, spare parts can be ordered sooner and, in the case of foreign-made machines, does not incur the cost of transporting the service staff to the site: "Each machine has a remote diagnostic service and the device monitors continuously the operation, forces, temperatures, etc. In case the system signals or detects a malfunction or abrasion, we will be notified and then obviously we can request proper service for the machine".

In the case of a dairy producing company, it is worth examining two directions of technology, on the one hand, milking technology, and on the other hand, animal welfare equipment. They identified cattle by RFID chips hanging in their ears, which store plenty of data about them (see chapter Results and Discussion, Data analysis). The milking machine is set up manually, but the milking machine milks the cattle in 4-5 minutes and automatically stores quantitative and qualitative information: "The computer automatically calculates the expected milk from the previous days' milk production and lactation stage". Animal welfare fundamentally affects milk yield, so several "convenience" solutions can be observed at the farm. For cattle, temperatures above 25 degrees Celsius cause heat stress, so above this temperature limit, the water spray is switched on in the paddock, which automatically releases water more and more frequently as the temperature rises. Similarly, when the temperature limit is reached, the fans also turn on. The basically open side-walled paddocks allow good airflow, but in case of bad weather (rain, wind), a tarpaulin automatically lowers to protect the animals from discomfort.

The computer-determined feed composition is mixed in the feed mixer, which indicates how much nutrients should be added to each group of goods according to the uploaded plan. The fodder is poured along with the paddocks and can be consumed by the cows leaning out of the paddock. While eating, they inevitably break through the paddock, so a feed-sweeping robot walks through the paddocks several times during the day to dig it back to where the animals can reach it. The content of the feed is checked several times a week and the composition is revised if necessary.

At the dairy-producing company, the technology is not as integrated as in the pasta factory. The investments made focused on key processes to comply with food safety regulations which would not be possible otherwise. The system stores a lot of information about animals, skimmed milk, a significant part of which is prescriptive, while analysing the other part of the data allows creating an appropriate environment, nutrients, and caring for the animals. The data collected is used to increase animal welfare, formulate optimal feed, and determine workers 'performance pay. Although there is a significant amount of data generated that is stored on corporate servers, the issue of cybersecurity has not been addressed.

The dairy processing company makes developments in two directions. On the one hand, there are expectations from the parent company to improve productivity and carry out other digitalisation projects, and on the other hand, employees within the company are very creative and make suggestions for improvement. This company operates a very labour-intensive production process, which resource, however, is scarce. To replace the workforce, cobots (cooperative robots) have been implemented that can be operated safely among humans and take on monotonous, demanding or repetitive tasks: "Cobots are relatively smaller and therefore cheaper than large industrial robots and can be implemented amongst humans. Work safety is very important". A similar palletizing robot works as at the pasta manufacturer, which is not an own, customized development, a readymade system has been purchased and adapted. Like the dairy producer, a lot of data is collected (Results and discussion, Data analysis)) and processed, some of which are used to fit regulations and others for process development and efficiency. The data is stored partly locally and partly at a group level 
at central data storage, while analyses are carried out at all levels. The goal is to be able to intervene immediately as soon as an emergency warning is generated.

The new plant at the meat processing company has been specifically built to give management a complete overview of the process through built-in sensors. Here, the process of raw material arrival, receiving, and first processing is monitored, which are essential for the resale of the raw material or processing by further plants. Based on the sensor data, the net expected amount of gross incoming raw material can be better planned, the system not only calculates the loss (gross-net deviation) but also monitors the raw material weight, moisture, and protein content: "We use sensors in the raw material processing. This is repeated at several stages during the process." Once again, the goal is the possibility of immediate intervention. Although they cannot yet measure efficiency per worker, only at the production line level, they can already use the data for performance pay. Another element of development was the equipment of machines with preventive maintenance functions to reduce downtime. The company used lean solutions before, and the current developments were also coordinated by this team.

Overall, in connection with the development of technology, most companies find proper digital solutions, the connection of machines to the network is realized, data collection works, it is partly analysed and used in some part of decision-making. An I4.0 solution can be observed in the pasta factory, in which machines are not only connected to each other, but the production forms a unified whole with the automated warehouse and logistics processes, and automated, robotic processes can also be observed. Besides digitalisation, robotics and automation are already appearing at the milk processing company, but the solutions do not form a system, isolated developments can be observed.

There are many European Union and Hungarian state funds available for technological developments. The majority of companies examined have won tenders and have also been able to achieve a favourable return on their deductible. However, participation in further tenders is now so expensive because of the price of the technology and the construction, and so difficult to find a contractor for the project, that these jeopardize the project to fit in the budget and the time frame at all.

\section{Employees}

The purpose of analysing this dimension is to examine how the company involves its employees in digital developments. We also examined what jobs were created and transformed as a result of new technologies and process developments.

Contrary to what is described in the literature (Deloitte, 2015; Carpenter and Wyman, 2017), the examined companies not only do not decrease staff due to technological developments, but rather struggle with labour shortages, or, only improvements can help to avoid shortage.

The pasta company has always used a lot of automation in production, so the blue-collar staff was low in the past, too. Currently, the pasta factory employs approximately 100 people, producing more than 50,000 tons of pasta per year, in three shifts a day. As a result of the current developments, they realize that they will increasingly need workers who can operate, maintain, or program machines. In this respect, they have no problems yet, but the increase in staff has begun. The number of maintenance staff has doubled in the last 5 years and the organisation of the technical directorate has also expanded. In total, 14 people are already working to ensure the technical maintenance of production. Because automation was already present in production processes in the past, accepting the new technology with workers was not a problem, although generational differences appear (young people are basically easier to get used to working with a robot, they also learn programming faster than their older peers). "By automating a lot of things, we've triggered a lot of manual work. On the other hand, there is a great need for a staff that can not only operate these machines but also understands them and intervene if necessary" the interviewee said. Workers on the production line are also involved in generating development ideas, and company management is open to development proposals from any level.

The dairy production company is faced with the situation that the improvements made it possible that they have enough manpower: "There is a growing shortage of manpower here, and unfortunately I have to say that it is not a question of money. Because if I were to pay twice as much, there would certainly not be more milkers who want to do it." The roles of veterinarians, animal husbandry engineer, and feed manager have been expanded 
through digitisation, they keep electronic records, upload animal data to the central register, compile reports that summarise and analyse milking results, and electronically plan the fodder, which is assembled and loaded into a feed mixer. Their task is to query and compile new types of reports from the available data, which can be further developed. At the company, development ideas come more from white-collar employees, and investment planning is a top management decision. The company also faced the dilemma of knowing that more advanced technology would be available, and they would buy it, but there are very few professionals in the country who could be able to operate it. This is seen as a serious constraint of further development.

The dairy processing company is struggling with labour shortages. The unemployment rate in the region is very low (1-2\%), so they often have to hire workers they consider just right to do the job, and the fluctuation is high. Its developments have also been driven partly by the creation or assistance of jobs in areas with the greatest labour shortages and fluctuation. The workers accept the technology, are happy to work with the cobots, and experience it as a modern technological environment. On the one hand, the company receives the development directions from the parent company, on the other hand, generates them from the inside. The source of the latter is typically engineering, quality assurance, or plant management. However, in the case of a problem, they first look at the group level, whether a similar one has arisen somewhere amongst the affiliates, and how it has been solved there: "Colleagues here are very creative, there are also Western European factories asking for advice from us". For the time being, the company does not feel that the structure of the workforce is changing due to digitalisation and robotization, but they see that in 5 years they will need many more technicians, PLC programmers, and maintainers.

For the meat processing company, the labour shortage is also a typical problem. There are jobs in which learning manual work is very timeconsuming, and with the knowledge gained, many are more likely to be move to Western Europe. That is why one of the drivers of the developments is the replacement of jobs where there is a high risk of emigration. However, there are complex manual tasks that cannot be taught to a robot: "I see only partial opportunities (for the introduction of 14.0 devices) in production and more in logistics especially in warehousing. It is also important in operations and maintenance."
Sources of development ideas can be both bluecollar and white-collar workers, and the company is open to initiatives, and proposals are rewarded if they are successful.

Based on the above, it can be seen that companies perceive that digitalisation is changing expectations of the workforce, making jobs more complex, and requiring much more technological knowledge. However, labour shortage affects food companies seriously, the suction power of other sectors is very strong.

\section{Company culture}

In examining corporate culture, we looked at how open companies are to innovation, how well their employees have the opportunity to make suggestions, and how knowledge sharing takes place in the company.

Although the implementation of I4.0-related development was partly forced for most of the companies, the firms made very important and significant investments. To maintain growth, the pasta company has embarked on the development of a new, modern production unit, which has made it a significant player not only in Hungary but also in Central-Eastern Europe. The commitment of senior management and the involvement of employees should be highlighted as a factor of success. When choosing the technology, it was a clear consideration to choose one, which can serve competitiveness, not to seek the cheapest solution. An explicit knowledge management system does not work $\mathrm{t}$ the company, but since it is a small organisation, the communication takes place directly: "Training has always been an important aspect here in the pasta factory."

The dairy producing company opted for a large-scale and fundamental technological change to survive. The decision was made by the top management, but like the pasta company, the management mobilized great energies so that the decision-makers of the investment could learn about the technological possibilities. They went on study trips abroad to get to know and learn about the technology, so they sacrificed a lot to make an informed decision and to prepare for the operation: "We constantly - with the support of the top management - go on study trips and employ consultants who are currently introducing new things, novelties". In terms of corporate culture, employees are expected to be constantly learning and open to change. 
The dairy processing company has taken many solutions from the parent company. Innovation is very important centrally, and central digital developments must be carried out. At the group level, a knowledge-sharing portal is now being set up, in which subsidiaries upload the solution to a specific problem, their best practices. They make common knowledge for the group, which can be used by any other subsidiary. Bottom-up initiatives have a culture in local development: "Engineering brings together (the ideas), designs a solution for it, calculates how much it would cost, what will improve, how long it can be realized, what savings can be expected".

The meat company has also taken great strides towards modernization, economic stability, and technological development. According to the expert interviewed, it is very important to have a management in a company that has a vision and can assess where the industry is heading over the next 10 years and dares to make the right decisions and takes risks. As the interviewee says: "Here you have to decide not only based on return, but there will be other aspects as well, e.g., where the industry will be in 10 years, what consumer needs will be and what technology will be able to meet it". In recent years, a culture of acceptance of bottom-up initiatives has also developed in this organisation, but we cannot talk about a knowledgesharing system.

In the previous chapters, we got to know four organisations committed to innovation and embarking on change. Corporate culture also supports development initiatives in all places, whether they come from below or from above, but the operation of a knowledge management system - except for a company with an international background - is not typical.

\section{Conclusion}

In our study, we examined the steps taken by the food industry towards digitalisation and I4.0. We sought to increase the validity of the research by interviewing actors from the three most important sub-sectors of the Hungarian food economy.

The main finding of the study is that there are food industry developments in Hungary that take advantage of the opportunities offered by digitalisation and I4.0. Table 3 is following the same structure and logic we created within our analytical framework. Related to strategy and organisation dimension, two main questions were asked. On the one hand, whether the I4.0 strategy exists or not, and on the other hand if the need for organisational changes is obvious for the management and already started. As the table shows, only the dairy processing company has an I4.0 strategy (on an international level due to its membership of an international group), and only the pasta manufacturer recognized the need for organisational changes due to the new positions (IT, maintenance). Data collection and data analysis questions are raised in the second dimension, where we could observe the developing status of the companies. Within the technology dimension, we distinguished the field of solutions applied. It came as a question, whether the whole process integrates I4.0 technologies or only it can be found partially, in isolated solutions or supportive processes. In connection with employees' dimension, we concluded that usage of I4.0 technologies in none of the cases ended up with less need for human work but on the contrary. It helped to decrease the risk due to the human workforce shortage. Also, the need for new positions (maintenance, IT) appeared in our cases. Related to the involvement of the employees we observed an in-progress status of the companies, as the developments, ideas come mainly from the top management. Our last dimension is the company culture with two areas: the openness for innovation and knowledge sharing. We found that all our cases belong to an in-progress openness for innovation as the food industry is typically follower compared to very innovative industries. The knowledge-sharing aspect of the companies differed significantly in our research. In two cases, formal or informal levels of knowledge sharing practices can be observed on group levels. However, in the other two cases, knowledge sharing is reaching only a basic level as it is informal and occasional. The main results are summarised in Table 3.

According to Kürthy et al. (2016), the Hungarian food industry is lagging behind its Western competitors in terms of efficiency and technology, although export activity significantly boosts the sales revenue of enterprises. This is also evident in the pasta factory which has reached its capacity limit and has committed itself to a growth strategy that it plans to build on exports by setting up a new plant. To achieve higher efficiency, companies can best help to implement further optimisation and increase their competitiveness by purchasing state-of-the-art technology and analysing the data it produces. Consistent 


\begin{tabular}{|c|c|c|c|c|c|}
\hline Results & & $\begin{array}{c}\text { Pasta } \\
\text { manufacturer }\end{array}$ & Dairy producer & Dairy processor & Meat processor \\
\hline \multirow{2}{*}{$\begin{array}{l}\text { Strategy } \\
\text { and organization }\end{array}$} & I4.0 strategy & No & No & $\begin{array}{c}\text { Yes, on } \\
\text { international level }\end{array}$ & No \\
\hline & $\begin{array}{c}\text { Organizational } \\
\text { changes }\end{array}$ & Embryonic & No & No & No \\
\hline \multirow{2}{*}{ Data analysis } & Data collection & Extensive & Extensive & Developing & Limited \\
\hline & Data analysis & Developing & Developing & Developing & Developing \\
\hline Technology & $\begin{array}{l}\text { Automation, } \\
\text { robotization }\end{array}$ & Integrated process & Isolated solutions & Isolated solutions & $\begin{array}{l}\text { In supportive } \\
\text { processes }\end{array}$ \\
\hline \multirow[t]{2}{*}{ Employees } & Cadre personnel & $\begin{array}{c}\text { Increasing } \\
\text { in maintenance }\end{array}$ & Shortage & Shortage & Shortage \\
\hline & Involvement & In progress & No & In progress & In progress \\
\hline \multirow{2}{*}{ Company culture } & $\begin{array}{c}\text { Openness } \\
\text { for innovation }\end{array}$ & In progress & In progress & In progress & In progress \\
\hline & $\begin{array}{l}\text { Knowledge } \\
\text { sharing }\end{array}$ & $\begin{array}{l}\text { Group level, } \\
\text { informal }\end{array}$ & Basic & $\begin{array}{c}\text { Formalized, on } \\
\text { international level }\end{array}$ & Basic \\
\hline
\end{tabular}

Source: own editing

Table 3: Main findings of the study.

with the Simutech (2016) survey, interviewees reported significant investments (pasta, milk producer, and meat processor) in which decision was based not on the price of the technology rather on its knowledge and capabilities. One of the most important functions is predictive maintenance, data processing, in which they are still working on the exploitation of opportunities. The low prevalence of $\mathrm{I} 4.0$ is indicated by the fact that organisational changes were not typical at the companies, but rather the increase in the number of technical and maintenance departments.

Continuous quality control and improvement is also a central element of corporate development (Santeramo et al., 2018). Productivity has improved, enabling customers to access a wider range of products at affordable prices (pasta), improving and controlling product content (milk production, meat processing), and paying attention to allergens at a higher level (dairy processor).

The results of our study are completely consistent with the research of Bibi et al. (2017), Carpenter and Wyman (2017), and Bottani and Rizzi (2008), according to which the development of technology is an important tool for complying with always tightening regulations. Barcodes play a primary role in tracking, but RFID chips are used to identify and track cows at the dairy farm RFID (or barcode) -based traceability covering the entire supply chain as Tian (2016) suggest is not yet available, and supply chain actors are still looking for a solution to the problem individually. In the same way, we could not find evidence of applying (or at least planning to apply) blockchain technology in the analysed firms.

Our research revealed the effects of digitalisation on the food industry companies. We highlighted that besides the technological development firms have to adapt to their organisation, as well, and the role of human factors in success is essential. Success does not depend only on the technology acceptance of blue-collar workers, but also on their development ideas as well as the top-management engagement. Our important finding is that although food security regulations force companies to technology - especially IT - development, and besides the high cost it is also challenging in terms of data security, storage, and processing capacity and methodology.

In our exploratory study, four corporate practices were introduced which also can serve as excellent benchmarks. We highlighted that although I4.0 and digitisation appear in various ways in the different companies and sub-sectors, their impact is far from limited to production, affecting several levels of organisational operation.

The research also has limitations. The case study method and the four analysed companies do not allow generalising the results, although it is excellent in revealing how digitalisation affects companies and aims to gain a better understanding of what and why firms decide and do to move towards I4.0. Regarding the future research prospects, we are intended to track the companies further and follow up their ways on the road of digitalisation. We are eager to know how they continue the development 
and how their organisation will transform thank to I4.0.

\section{Acknowledgments}

This research was supported by the project "Aspects on the development of intelligent, sustainable,

Corresponding authors

Judit Nagy, PhD, associate professor

Corvinus University of Budapest, 8 Fövám tér, 1093 Budapest, Hungary

Phone:+361482 5232,E-mail: judit.nagy@uni-corvinus.hu

\section{References}

[1] Bibi, F., Guillaume, C., Gontard, N. and Sorli, B. (2017) "A review: RFID technology having sensing aptitudes for food industry and their contribution to tracking and monitoring of food products", Trends in Food Science \& Technology, Vol. 62, pp. 91-103. ISSN 0924-2244. DOI 10.1016/j.tifs.2017.01.013.

[2] Bottani, E. and Rizzi, A. (2008) "Economical assessment of the impact of RFID technology and EPC system on the fast-moving consumer goods supply chain", International Journal of Production Economics, Vol. 112, No. 2, pp. 548-569. ISSN 0925-5273. DOI 10.1016/j.ijpe.2007.05.007.

[3] Brettel, M., Friederichsen, N., Keller, M. and Rosenberg, M. (2014) "How virtualization, decentralization and network building change the manufacturing landscape: An Industry 4.0 Perspective", International Journal of Mechanical, Industrial Science and Engineering, Vol. 8, No. 1, pp. 37-44. ISSN 0020-7403.

[4] Carlozo, L. (2017) "What is blockchain?", Journal of Accountancy, Vol. 224, No. 1, p. 29. ISSN 1945-0729.

[5] Carpenter, G. and Wyman, O. (2017) "Food manufacturing - Are you ready for Industry 4.0?", Marsh Report, Marsh and McLennan Companies, United Kingdom [Online]. Available: https://www.marsh.com/uk/insights/research/food-manufacturing-are-you-ready-for-industry.html [Accessed: 5 June 2019].

[6] Chaime, J. (2020) “World population: 2020 overview”. [Online]. Available: https://yaleglobal.yale. edu/content/world-population-2020-overview [Accessed: 29 April 2020].

[7] Dalenogare, L. S., Benitez, G. B., Ayala, N. F. and Frank, A. G. (2018) “The expected contribution of Industry 4.0 technologies for industrial performance", International Journal of Production Economics, Vol. 204, pp. 383-394. ISSN 0925-5273. DOI 10.1016/j.ijpe.2018.08.019.

[8] Deloitte (2015) “Industry 4.0 - An introduction", Deloitte, Hollandia [Online]. Available: https:// www2.deloitte.com/content/dam/Deloitte/be/Documents/Operations/2015_Industry\%204\%20 0\%20Report\%20vFinal.pdf [Accessed: 20 April 2019].

[9] Demartini, M., Pinna, C., Tonelli, F., Terzi, S., Sansone, C. and Testa, C. (2018) "Food industry digitalization: from challenges and trends to opportunities and solutions", IFAC-PapersOnLine, Vol. 51, No. 11, pp. 1371-1378. ISSN 2405-8963. DOI 10.1016/j.ifacol.2018.08.337.

[10] Demeter, K., Losonci, D. and Nagy, J. (2020) "Road to digital manufacturing - A longitudinal case-based analysis", Journal of Manufacturing Technology Management, ISSN 1741-038X. DOI 10.1108/JMTM-06-2019-0226.

[11] Denzin, N. K. and Lincoln, Y. S. (Eds) (2011) “The SAGE Handbook of Qualitative Research”, Sage, Thousand Oaks, USA. ISBN 978-1-4129-7417-2. 
[12] Dworschak, B. and Zaiser, H. (2014) "Competences for cyber-physical systems in manufacturingfirst findings and scenarios", Procedia CIRP, Vol. 25, pp. 345-350. ISSN 2212-8271. DOI 10.1016/j.procir.2014.10.048.

[13] Fettig, K., Gačić, T., Köskal, A., Kühn, A. and Stuber, F. (2018) "Impact of Industry 4.0 on Organisational Structures", In 2018 IEEE International Conference on Engineering, Technology and Innovation (ICE/ITMC), pp. 1-8. DOI 10.1109/ICE.2018.8436284.

[14] Frey, C. B. and Osborne, M. A. (2017) "The future of employment: how susceptible are jobs to computerisation?", Technological Forecasting and Social Change, Vol. 114, pp. 254-280. ISSN 0040-1625. DOI 10.1016/j.techfore.2016.08.019.

[15] Gauger, C., Gehres, B., Quinn, M., Schmieg, F. and Xu, G. (2017) "Building the digital car company of the future", The Boston Consulting Group, USA, April.

[16] Geissbauer, R., Vedso, J. and Schrauf, S. (2016) "Industry 4.0: Building the digital enterprise". [Online]. Available: https://www.pwc.com/gx/en/industries/industries-4.0/landing-page/industry4.0-building-your-digital-enterprise-april-2016.pdf [Accessed: 20 April 2019].

[17] Gill, M. and VanBoskirk, S. (2016) "The digital maturity model 4.0. Benchmarks: Digital Transformation Playbook".

[18] Gracel, J. and Lebkowski, P. (2018) "The Concept of Industry 4.0-Related Manufacturing Technology Maturity Model (ManuTech Maturity Model-MTMM)", Decision Making in Manufacturing and Services, Vol. 12, No. 1-2, pp. 17-31. ISSN 2300-7087. DOI 10.7494/dmms.2018.12.1-2.17.

[19] Hermann, M., Pentek, T., and Otto, B. (2016) "Design principles for industrie 4.0 scenarios", In $201649^{\text {th }}$ Hawaii international conference on system sciences (HICSS), pp. 3928-3937. E-ISBN 978-0-7695-5670-3. ISSN 1530-1605. DOI 10.1109/HICSS.2016.488.

[20] Hofmann, E. and Rüsch, M. (2017) "Industry 4.0 and the current status as well as future prospects on logistics", Computers in Industry, Vol. 89, pp. 23-34. ISSN 0166-3615. DOI 10.1016/j.compind.2017.04.002.

[21] Horváth, D. and Szabó, R. Z. (2019) "Driving forces and barriers of Industry 4.0: Do multinational and small and medium-sized companies have equal opportunities?", Technological Forecasting and Social Change, Vol. 146, pp. 119-132. ISSN 0040-1625. DOI 10.1016/j.techfore.2019.05.021.

[22] Ilie-Zudor, E., Kemény, Z., Van Blommestein, F., Monostori, L. and Van Der Meulen, A. (2011) "A survey of applications and requirements of unique identification systems and RFID techniques", Computers in Industry, Vol. 62, No. 3, pp. 227-252. ISSN 0166-3615. DOI 10.1016/j.compind.2010.10.004.

[23] Kittipanya-ngam, P. and Tan, K. H. (2020) "A framework for food supply chain digitalization: lessons from Thailand", Production Planning \& Control, Vol. 31, No. 2-3, pp. 158-172. E-ISSN 1366-5871. ISSN 0953-7287. DOI 10.1080/09537287.2019.1631462.

[24] Kürthy, G., Dudás, G. and Felkai, B. O. (Eds.) (2016) “A magyarországi élelmiszeripar helyzete és jövöképe"(The current situation and the future of the Hungarian food industry), Agrárgazdasági Kutató Intézet, Budapest. ISBN 978-963-491-599-7. (in Hungarian).

[25] Lichtblau, K., Stich, V., Bertenrath, R., Blum, M., Bleider, M., Millack, A. and Schröter, M. (2015) "IMPULS-industrie 4.0-readiness", Impuls-Stiftung des VDMA, Aachen-Köln.

[26] Nagy, J., Oláh, J., Erdei, E., Máté, D. and Popp, J. (2018) "The role and impact of industry 4.0 and the internet of things on the business strategy of the value chain - The case of Hungary", Sustainability, Vol. 10, No. 10, p. 3491. ISSN 2071-1050. DOI 10.3390/su10103491.

[27] Pagani, M. and Pardo, C. (2017) "The impact of digital technology on relationships in a business network", Industrial Marketing Management, Vol. 67, pp. 185-192. ISSN 0019-8501. DOI 10.1016/j.indmarman.2017.08.009. 
[28] Santeramo, F. G., Carlucci, D., De Devitiis, B., Seccia, A., Stasi, A., Viscecchia, R. and Nardone, G. (2018) "Emerging trends in European food, diets and food industry", Food Research International, Vol. 104, pp. 39-47. ISSN 0963-9969. DOI 10.1016/j.foodres.2017.10.039.

[29] Schuh, G., Anderl, R., Gausemeier, J., Ten Hompel, M. and Wahlster, W. (Eds.). (2017) "Industrie 4.0 Maturity Index - Managing the Digital Transformation of Companies", Munich: Herbert Utz.

[30] Schumacher, A., Erol, S. and Sihn, W. (2016) "A maturity model for assessing Industry 4.0 readiness and maturity of manufacturing enterprises", Procedia Cirp, Vol. 52, pp. 161-166. ISSN 2212-8271. DOI 10.1016/j.procir.2016.07.040.

[31] Sen, K., Durakbasa, N., Erdol, H., Berber, T., Bas, G. and Sevik, U. (2017) "Implementation of digitalization in food industry", DAAAM International Scientific Book, pp. 91-104. ISSN 1726-9687. DOI 10.2507/daaam.scibook.2017.08.

[32] Simutech (2016) “Industry 4.0: How the food industry must adapt to survive”, Simutech Multimedia, White Paper, Kanada. [Online]. Available: https://www.simutechmultimedia.com/downloads/ whitepapers/simutech-whitepaper-industry-4.0.pdf [Accessed: 5. June 2019].

[33] Tian, F. (2016) “An agri-food supply chain traceability system for China based on RFID \& blockchain technology", In $201613^{\text {th }}$ international conference on service systems and service management (ICSSSM), pp. 1-6. E-ISSN 2161-1904. DOI 10.1109/ICSSSM.2016.7538424.

[34] Tse, D., Zhang, B., Yang, Y., Cheng, C. and Mu, H. (2017) "Blockchain application in food supply information security", In 2017 IEEE International Conference on Industrial Engineering and Engineering Management (IEEM), pp. 1357-1361. E-ISSN 2157-362X. DOI 10.1109/IEEM.2017.8290114.

[35] World Economic Forum (2018) "The system initiative on shaping the future of food security and agriculture". [Online]. Available: https://weforum.ent.box.com/v/FSA [Accessed: 26 Feb. 2019].

[36] Yin, R. K. (2011) “Applications of case study research”, Sage Publications, USA, pp. 4-6. ISBN 978-1-4129-8916-9. 